\title{
THE FLIPPED CLASSROOM FOR COLLEGE STUDENTS: AN EVALUATION OF RESEARCH AND TRENDS FROM TRADITIONAL AND ONLINE FACULTY
}

\author{
Rebekah Dyer, Grand Canyon University \\ Thomas Dyer, Grand Canyon University
}

The researchers of this article offer a diverse perspective in explaining and implementing teaching practices. One is an Associate Professor in the College of Education teaching undergraduate and graduate courses specific to the field of special education in a traditional setting and occasionally teaching online classes as an adjunct. She has been teaching at the university level for over eight years. The other researcher is an Associate Professor in the College of Humanities and Social Sciences who is a full-time online faculty member teaching undergraduate students. He has been teaching full-time online for over eight years and teaches traditional classes as an adjunct. Both faculty members utilize the same Learning Management System (LMS) to deliver their courses. They have both noticed a shift in how students prefer to learn. Together they pondered how the flipped classroom model can impact both online and traditional students and instructors.

With the constant technological advances, students have developed a preference for active, collaborative environments (Tsai \& Chiang, 2018). Students desire practical, real-world experiences to connect with the content they are learning. A large part of being a teacher involves collaboration. Teachers work in grade level groups, content specific groups, and/or groups based on areas of specialty. Teachers collaborate to develop lesson plans, determine appropriate strategies to support students, and develop assessments. It is important for students in teacher preparation programs to have strong skills for effective collaboration. These skills include communication, organization, and ability to respect differences and value of others' ideas and input. The goal of faculty is to prepare students for their future careers. Thus, it is important to give them the opportunity to practice collaboration with others.
An obstacle to providing greater collaboration opportunities is time. In a traditional classroom the majority of class time is spent teaching content. The traditional college classroom involves direction instruction, where the instructor lectures while the students take notes on the content. The students then work on the assignments related to that content on their own time. They are not able to work with the content while collaborating with other future teachers. Online students suffer from some of the same issues. Most universities employ online adjunct faculty who are part-time and typically have limited availability, whereas full-time online faculty instructors have greater availability and can assist students quickly and efficiently through many means.

The solution to this obstacle was the implementation of the flipped classroom model. The flipped classroom involves providing different tools for the students to use to review the content prior to the class meeting time (Dickenson, 2016). When the class meets, the instructors utilize real-world activities and/or projects for the students to work on in class. This approach to teaching maximizes time for the students to collaborate, investigate the content, and problem solve. The flipped classroom can also be referred to as the inverted classroom (Dickenson, 2016).

The concept of the flipped classroom is not new as it has been around since 2006 . Undergraduate students have shared positive feedback regarding this teaching model in end-ofcourse surveys collected for research. In studies, the students who expressed they preferred this type of instruction increased in their achievement (Phillips \& O'Flahery, 2019). The students felt that the flipped classroom was more of a learnercentered approach verses direct instruction, which is teacher-centered. The students discussed 


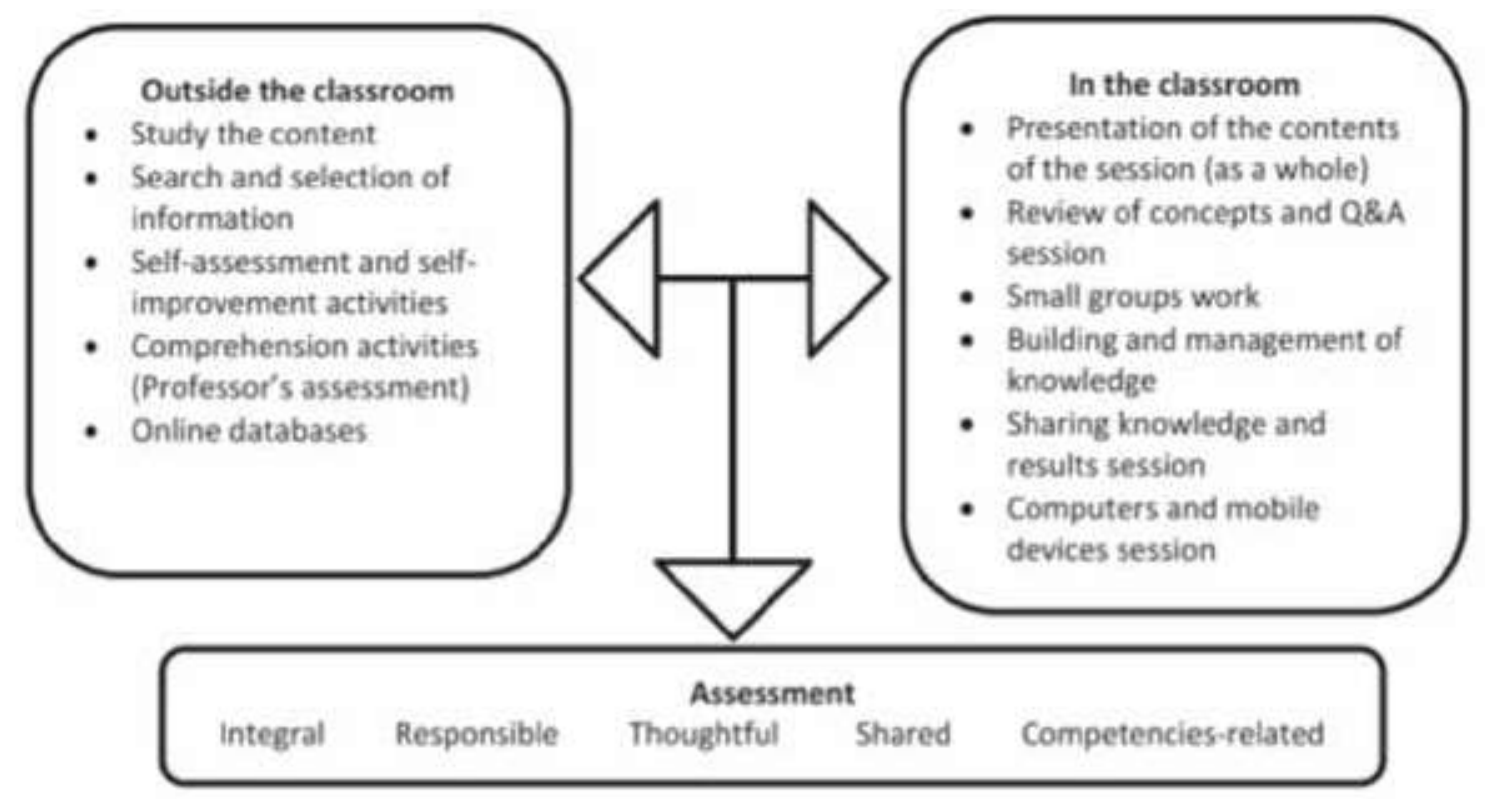

(Flores, del-Arco \& Silva, 2016)

the feeling of community they experienced in the flipped classroom, and they were able to connect more with their colleagues. The students were able to develop their knowledge both independently and with their peers, which deepened their understanding (Dickenson, 2016). It has been determined students experience a higher rate of learning gains when they experience inquirybased and cooperative learning during class time (Jensen-Vallin, 2017; McCallum, Schultz, Sellke, \& Spartz, 2015). This is due in part to the process of students critically thinking about the content they are learning and applying it to real-world scenarios, rather than simply reciting facts (Lim, Kim, Lee, Kim, \& Han, 2014).

Online learning is already conducive to utilizing a flipped classroom model. Flipped classrooms allow learners to be independent and go at their own pace, offer flexibility of when and where resources are accessed, and use class time to engage students in discussion rather than direct instruction (Phillips \& O'Flaherty, 2019). This perfectly describes a typical online asynchronous classroom. Faculty who teach online should utilize Web 2.0 tools to create resources for students aimed at increasing engagement and a deeper understanding of course content and assignment expectations. Online faculty can invest in flipped online classroom strategies by utilizing technology tools that support communication (i.e., the resource Remind, which offers a one- or two-way text communication); offering direct feedback and clear instruction (i.e., the resource Loom, which uses video feedback and instruction); and creating space for social presence (i.e., the resource Flipgrid, which offers two-way video sharing).

Technology can enhance online course content, but must be supported by appropriate design and intentional faculty focus (Phillips, McNaught, \& Kennedy, 2012). Web 2.0 tools such as Remind, Zoom, Loom, and Flipgrid can help bridge provide students feel connected to the instructor and their peers. Faculty can record videos that walk students through assignments and pertinent content delivering this information early in the week so students have the time to ask questions. Faculty can also provide practice quizzes, utilizing tools such as Quizizz, generating more opportunity for students to question their understanding of the material. These activities serve as a medium to equip students in remembering, understanding, and applying previous and new knowledge. More research is needed to measure the precise effectiveness of the use of technology in the online classroom. Poor use of technology or a lack of instructor understanding on its use may lead to lower rates of student retention, success, and collaboration (Cooper \& Scriven, 2017).

The six elements of a successful flipped classroom are professional development for academics, 
professional development for instructional designers, learning supports for students, input from academics, input from instructional designers, and input from students (Miles \& Fogget 2016). Most universities have implemented some of these components in different ways. Input from instructional designers has become more common, but this needs to be supported with professional development for the instructional designers to ensure they are aware of the most current technologies and strategies for preparing and delivering online content (Miles \& Fogget 2016). Instructors must look to apply technology that fills in those instructional gaps (Duta and Martinez, 2015).

It is essential that all stakeholders (academic leadership, faculty, instructional designers, and students) have input regarding the presentation of the content. Data should be collected and analyzed continuously to ensure the presentation of the content is effective. Data analyses can be conducted by the different stakeholders independently, but should also be reviewed as a team to provide the most comprehensive plan for moving forward. The inclusion of the students in the process encourages the culture of the student as a partner with the university (Miles \& Foggett, 2016).

As we have implemented the flipped or inverted classroom model, our students have experienced a large number of opportunities to collaborate with their peers. They have had the opportunity to collaborate with each other on presentations, projections, essay writing, lesson planning, individualized education plans for students with disabilities, and overall brainstorming of effective teaching strategies. They have experienced the need for working through conflicts in their collaboration, interpretation of different ideas, and organization of information. These are all skills that are required in many careers. The flipped classroom has proven to be a positive influence for the students and instructors.

Research has indicated an additional unexpected benefit of the flipped classroom-relationship building. Students have reported an increased ability to develop relationships with their peers and instructors through the flipped classroom (McCollum, Fleming, Plotnikoff \& Skagen, 2017). The different relationships impacted include, peer to peer, peer to peer leader, and student to instructor.
Faculty who implement personalized technology in the flipped classroom may amplify engagement between student and instructor by making the material fun and relevant (Dyer, Steele, Larson, \& Holbeck, 2015). As the relationships are developed they have a positive impact on the students' academic development as well. In order for the students to successfully problem-solve with the content for different activities, projects and assignments, they need to effectively develop these different types of relationships. The use of technology may increase the accessibility and opportunity, providing space for students and faculty to build relationships and facilitate academic achievement (Duta \& Martinez, 2015). Working collaboratively and building different types of relationships allows students and instructors to build on each other's strengths.

As professors we strive to model teaching strategies that the students can then use in their future careers. One of the most important effective teaching strategies is to promote student engagement. The more engaged students are in their learning, the more likely they are to retain the content they are learning. We feel that the implementation of the flipped classroom has proven to be another strategy that faculty can model for the students to take into their future careers and their own classroom to benefit their students.

The planning and implementation of the flipped classroom does take time. The content and assignments of the courses should be mapped out over the course of the class sessions in the semester. The instructor will need to determine what activities, projects, and assignments will be conducted during class time. Then, the content will need to be organized in a way that the students can effectively find and review the information prior to the class sessions. In addition, the instructor should take the time to explain and discuss the flipped classroom model with the students and ask for feedback continuously. Teaching methods are essential to a successful course. Communicating clear expectations provides success for both the students and the instructor (Tsai \& Chiang, 2018). This will provide the opportunity modifications, if needed, throughout the course. Faculty may run into resistance to change. Any change in the classroom is dependent upon what faculty do and think; therefore, the faculties role in implementing 
classroom strategies is essential (Stîngu \& Iftimescu, 2016).

It is crucial for educators to be mindful of changing trends, including technological advances. As society changes, how students learn and interact with content changes as well (Molbaek, 2018). In order to be a successful teacher, the instruction needs to align with the current needs of the students. If we are not aware of those current needs, we are not providing adequate strategies to set our students up for success in the classroom (Molbaek, 2018). The flipped classroom is aligned with the current needs of students, who want to interact with the content and learn in practical ways (Tsai \& Chiang, 2018). 


\section{References}

Cooper, T., \& Scriven, R. (2017). Communities of inquiry in curriculum approach to online learning: Strengths and limitations in context. Australasian Journal of Educational Technology, 33(4), 22-37. doi-org.lopes.idm.oclc. org/10.14742/ajet.3026

Dickenson, P. (2016). The flipped classroom in a hybrid teacher education course: Teachers' self-efficacy and instructors' practices. Journal of Research in Innovative Teaching, 9(1), 78-89.

Duţă, Nicoleta. (2017). Online interactive resources and teaching tools for the classroom: Theoretical approaches in teachinglearning process. Euromentor Journal, 8(3), 103-124.

Duţă, Nicoleta, \& Martinez Rivera, Oscar. (2015). Between theory and practice: The importance of ICT in higher education as a tool for collaborative learning. Procedia-Social and Behavioral Sciences, 180, 1466-1473. doi:10.1016/j. sbspro.2015.02.294.

Dyer, T., Steele, J., Larson, E., \& Holbeck, R. (2015). Integrating technology into the online classroom through collaboration to increase student motivation. Journal of Instructional Research, 4, 126-133.

Flores, Ò., del-Arco, I., \& Silva, P. (2016). The flipped classroom model at the university: Analysis based on professors' and students' assessment in the educational field. International Journal of Educational Technology in Higher Education, 13(1), $1-12$.

Jensen-Vallin, J. (2017). Teaching students to formulate questions. PRIMUS, 27(2), 189-201.

Lim, C., Kim, S., Lee, J., Kim, H., \& Han, H. (2014). Comparative Case Study on Designing and Applying Flipped Classroom at Universities. International Association for Development of the Information Society, 11. International Association for Development of the Information Society.

McCallum, S., Schultz, J., Sellke, K., \& Spartz, J. (2015). An examination of the flipped classroom approach on college student academic involvement. International Journal of Teaching and Learning in Higher Education, 27(1), 42-55.

McCollum, B. M., Fleming, C. L., Plotnikoff, K. M., \& Skagen, D. N. (2017). Relationships in the flipped classroom. Canadian Journal for the Scholarship of Teaching and Learning, 8(3).

Miles, C. A., \& Fogget, K. (2016). Supporting our students to achieve academic success in the unfamiliar world of flipped and blended classrooms. Journal of University Teaching and Learning Practice, 13(4).
Molbaek, M. (2018). Inclusive teaching strategies-dimensions and agendas. International Journal of Inclusive Education, 22(10), 1048-1061.

Phillips, C., \& O'Flaherty, J. (2019). Evaluating nursing students' engagement in an online course using flipped virtual classrooms. Student Success, 1, 59. doi-org.lopes.idm.oclc. org/10.5204/ssj.v10i1.1098

Stîngu, M., \& Iftimescu, S. (2016). Changing pedagogy: The use of technology in educational support programs. Bucharest: "Carol I" National Defence University. doi:http://dx.doi. org/10.12753/2066-026X-16-098

Tsai, C-W., \& Chiang, I-C. (2018). The flipped college classroom: Conceptualized and re-conceptualized. Higher Education Research and Development, 37(6), 1317-1320. 